\title{
Prognostic Significance of Rab27A and Rab27B Expression in Esophageal Squamous Cell Cancer
}

This article was published in the following Dove Press journal:

Cancer Management and Research

\author{
Fengqiang $\mathrm{Yu}^{*}$ \\ Weihan $\mathrm{Wu}^{*}$ \\ Mingqiang Liang (1D* \\ Yu Huang \\ Chun Chen
}

Department of Thoracic Surgery, Fujian Medical University Union Hospital, Fuzhou, Fujian, People's Republic of China

*These authors contributed equally to this work
Correspondence: Chun Chen

Department of Thoracic Surgery, Fujian Medical University Union Hospital, \#29

Xinquan Road, Fuzhou, Fujian 35000I,

People's Republic of China

Tel +86 I33659|0325

Fax +86 59I-83357896-8408

Email chenchun0209@I63.com
Purpose: Rab27A and Rab27B, members of the Rab family of small GTPases, have aberrant expression and exert different roles in various cancers. However, their expression and potential prognostic values in esophageal squamous cell cancer (ESCC) still remain elusive. In the present study, we explored the association of Rab27A and Rab27B expression with clinical significance and prognosis in ESCC.

Patients and Methods: A total of 100 surgically resected ESCC tissues were examined to evaluate Rab27A and Rab27B expression levels using the immunohistochemistry method. The relationship of Rab27A and Rab27B with clinicopathological features and prognosis was analyzed. We also investigated the correlation between Rab27A and Rab27B through external and internal validation.

Results: High-expression Rab27A was found to be significantly correlated with $\mathrm{N}(p=0.045)$ and TNM ( $p=0.005$ ) stage, while up-regulated Rab27B was remarkably associated with $\mathrm{N}$ stage $(p=0.033)$, TNM stage $(p=0.009)$, and differentiation $(p=0.013)$. High expression of both Rab27A and Rab27B had a worse overall survival (OS) rate. In addition, multivariate Cox regression analyses were utilized to validate that Rab27B expression is an independent prognostic factor for unfavorable OS. Further combined analyses showed that the $\mathrm{Rab} 27 \mathrm{~A}^{\text {low }} / \mathrm{B}^{\text {low }}$ group had a superior OS rate than the Rab27 $\mathrm{A}^{\text {high }} / \mathrm{B}^{\text {low }}$ group, Rab27A $\mathrm{A}^{\text {low }}$ $\mathrm{B}^{\text {high }}$ group, and Rab27 $\mathrm{A}^{\text {high }} / \mathrm{B}^{\text {high }}$ group. Nevertheless, the latter three groups displayed rare significance between each two comparisons. Furthermore, our data demonstrated that Rab27A expression was positively correlated with Rab27B expression, which were also verified in TCGA datasets.

Conclusion: Rab27A and Rab27B expression levels could be potentially novel prognostic biomarkers in ESCC.

Keywords: Rab27A, Rab27B, esophageal squamous cell cancer, prognosis, survival analysis

\section{Introduction}

Esophageal cancer (EC) ranks seventh in terms of incidence and sixth in worldwide cancer-related death, responsible for an estimated 572,000 new cases and 509,000 deaths last year, respectively ${ }^{1}$. There are normally two major histologic subtypes, including esophageal squamous cell carcinoma (ESCC) and esophageal adenocarcinoma (EAC). ${ }^{2}$ As the most common histological type, ESCC mainly occurs in parts of Asia and sub-Saharan Africa, accounting for over $90 \%$ of EC cases. ${ }^{3}$ Due to the lack of specific biomarkers, most ESCC patients are diagnosed at a late stage. Even worse, some patients suffer from tumor distant metastasis and recurrence. Even if recent advancements have been improved in therapy strategy, its prognosis 
and the 5-year survival are still extremely poor. Therefore, it is necessary and urgent to identify more effective prognostic factors and therapeutic targets for patients with ESCC to improve clinical strategies.

Rab proteins are a family of small (20-29 kDa) monomeric Ras-like GTPases distributed in different intracellular compartments. The regulatory principle of Rab proteins predominantly depends on their ability to function as molecular switches that impose temporal and spatial regulation to membrane transport. ${ }^{4}$ Besides, Rab proteins can control diverse steps of vesicular trafficking, including budding, motility, docking and plasma membrane delivery, and fusion of various secretory vesicle types. ${ }^{5,6}$ Nearly $70 \mathrm{Rab}$ proteins and Rab-like proteins have been identified in humans. ${ }^{7}$ The Rab27 family of small GTPases is critically involved in vesicle exocytosis and exosome release, ${ }^{8,9}$ which exerts a key role of regulating the tumor microenvironment. The family mainly consists of two major members, Rab27A and Rab27B, which have been investigated closely associated with tumor malignancy and can be implied as a prognostic indicator in several cancers, including non-small cell lung cancer, colorectal cancer, hepatocellular carcinoma, clear cell renal cell carcinoma, and pancreatic cancer. ${ }^{10-13}$ However, the prognostic value of Rab27A and Rab27B in ESCC remains unknown. In the current study, we detected the expression levels of Rab27A and Rab27B, and explored their correlation with clinical characteristics and prognostic significance in ESCC. Additionally, the relationship between Rab27A and Rab27B expression in ESCC was further evaluated.

\section{Patients and Methods}

\section{Patient Collection}

A total of 100 patients who underwent esophagectomy were enrolled into this study from Fujian Medical University Union Hospital at the Department of Thoracic Surgery between March 2012 and December 2014. The cases were confirmed as ESCC. All tissue specimens were histologically confirmed with ESCC independently by two pathologists according to the 8th edition American Joint Committee on Cancer TNM staging system. ${ }^{14}$ Patients did not receive neoadjuvant chemotherapy or radiotherapy. Disease-free survival (DFS) and overall survival (OS) were calculated as the period from the date of surgery to the date of recurrence and death, respectively. The study was approved by Ethics Committee of Fujian Medical University Union Hospital and complied with the Declaration of Helsinki. All patients provided written informed consent.

\section{Immunohistochemistry (IHC)}

All tissues were fixed by formaldehyde, embedded in paraffin, and then serially cut into sections with $4 \mu \mathrm{m}$ thickness followed by hematoxylin and eosin-stained for histological observation. For immunohistochemical detection, the slides were deparaffinized in xylene and rehydrated and incubated with $3 \%$ hydrogen peroxide. Subsequent to microwave treatment in citrate buffer ( $\mathrm{pH}$ 6.0) for antigen retrieval, slides were incubated with monoclonal anti-Rab27A (1:50 dilution, ab55667; Abcam, Cambridge, UK) and polyclonal antiRab27B (1:200 dilution, ab229874) at $4{ }^{\circ} \mathrm{C}$ overnight. After incubation of coordinate secondary antibody, slides were stained with DAB solution and visualized under a light microscope.

\section{Results Determination}

The staining intensity of Rab27A and Rab27B was scored as negative (0), weak (1), moderate (2), and strong (3), while the percentage of positive tumor cells was semiquantitatively scored as $<5 \%$ (0), 5-30\% (1), 31-50\% (2), and $>50 \%$ (3). ${ }^{14}$ Multiplication of both scores was considered as the final score ranging from 0 to 9 . Score $\leq 2$ and score $>2$ was defined as the low expression group and the high expression group, respectively.

\section{Correlation Analysis Between Rab27A and Rab27B Expression in Esophageal Carcinoma}

To investigate the correlation between Rab27A and Rab27B expression in esophageal carcinoma, we used open access website GEPIA (http:/gepia.cancer-pku.cn/) to analyze esophageal carcinoma data from The Cancer Genome Atlas (TCGA). ${ }^{15}$ Apart from external data, we also performed internal validation in correlation analysis using IHC scores.

\section{Statistical Analysis}

All statistical analyses were performed using SPSS 22.0 statistical software. Pearson's chi-square test was carried out to analyze the correlation between Rab27A and Rab27B expression and clinical features. Univariate and multivariate analyses were conducted using the Cox proportional hazard model. The log rank test was performed to calculated the survival rate through Kaplan-Meier analysis. $p<0.05$ was considered statistically significant. 


\section{Results}

\section{Clinical Data of I00 ESCC Patients}

The clinical data of 100 cases are listed in Table 1 . The cohort consisted of 54 male and 46 female patients with a median age of 60.5 years, ranging from 41 to 78 . For tumor location, $61 \%$ of cases were thoracic middle carcinoma while the rest were upper or lower. There were 58 cases with tumor diameter $\leq 4 \mathrm{~cm}, 42$ cases with tumor diameter $>4 \mathrm{~cm}$. With respect to differentiation, high/moderate/poor account for $35 \%, 52 \%$, and $13 \%$, respectively. Based on $\mathrm{T}$ stage of primary tumor, $21 \%$ were $\mathrm{T} 1,9 \%$ were $\mathrm{T} 2,58 \%$ were $\mathrm{T} 3$, and $12 \%$ were T4. According to the presence of lymph node metastasis, 48\% cases were observed with node-positive (32\% had N1, 13\% had N2, and 3\% had N3 involvement). Among the enrolled cases, TNM staging was classified as two subgroups ( $49 \%$ in $\leq$ II and $51 \%$ in $>$ II).

\section{Correlations Between Rab27A and Rab27B Expression and Clinicopathological Features}

Rab27A and Rab27B expression in ESCC were examined using the IHC method. The representative picture of high and low expression of Rab27A and Rab27B is presented in Figure 1. Rab27A demonstrated nucleus staining and Rab27B

Table I Correlations Between Rab27A Expression and the Clinicopathological Features of ESCC Patients

\begin{tabular}{|c|c|c|c|c|c|}
\hline \multirow[t]{2}{*}{ Characteristics } & \multirow[t]{2}{*}{ No. Cases } & \multicolumn{4}{|l|}{ Rab27A } \\
\hline & & Low Expression & High Expression & $\chi^{2}$ & $p$ value \\
\hline Gender & & & & 2.227 & 0.136 \\
\hline Male & 54 & 26 & 28 & & \\
\hline Female & 46 & 29 & 17 & & \\
\hline Age (years) & & & & 0.000 & 0.984 \\
\hline$\leq 60$ & 51 & 28 & 23 & & \\
\hline$>60$ & 49 & 27 & 22 & & \\
\hline Location & & & & 0.51 & 0.821 \\
\hline Upper/lower & 39 & 22 & 17 & & \\
\hline Middle & 61 & 33 & 28 & & \\
\hline Tumor size & & & & 0.599 & 0.439 \\
\hline$\leq 4 \mathrm{~cm}$ & 58 & 30 & 28 & & \\
\hline$>4 \mathrm{~cm}$ & 42 & 25 & 17 & & \\
\hline Differentiation & & & & $\mathrm{I} .803$ & 0.406 \\
\hline High & 35 & 21 & 14 & & \\
\hline Moderate & 52 & 29 & 23 & & \\
\hline Poor & 13 & 5 & 8 & & \\
\hline $\mathbf{T}$ (Primary tumor) & & & & 2.126 & 0.547 \\
\hline $\mathrm{TI}$ & 21 & 10 & 11 & & \\
\hline $\mathrm{T} 2$ & 9 & 6 & 3 & & \\
\hline $\mathrm{T} 3$ & 58 & 34 & 24 & & \\
\hline $\mathrm{T} 4$ & 12 & 5 & 7 & & \\
\hline N (Lymph node metastasis) & & & & 8.068 & 0.045 \\
\hline No & 52 & 35 & 17 & & \\
\hline NI & 32 & 14 & 18 & & \\
\hline N2 & 13 & 4 & 9 & & \\
\hline N3 & 3 & 2 & I & & \\
\hline TNM stage & & & & 8.036 & 0.005 \\
\hline$\leq I I$ & 49 & 34 & 15 & & \\
\hline$>I I$ & 51 & 21 & 30 & & \\
\hline
\end{tabular}

Note: Significant results $(p<0.05)$ are given in bold.

Abbreviation: ESCC, esophageal squamous cell carcinoma. 

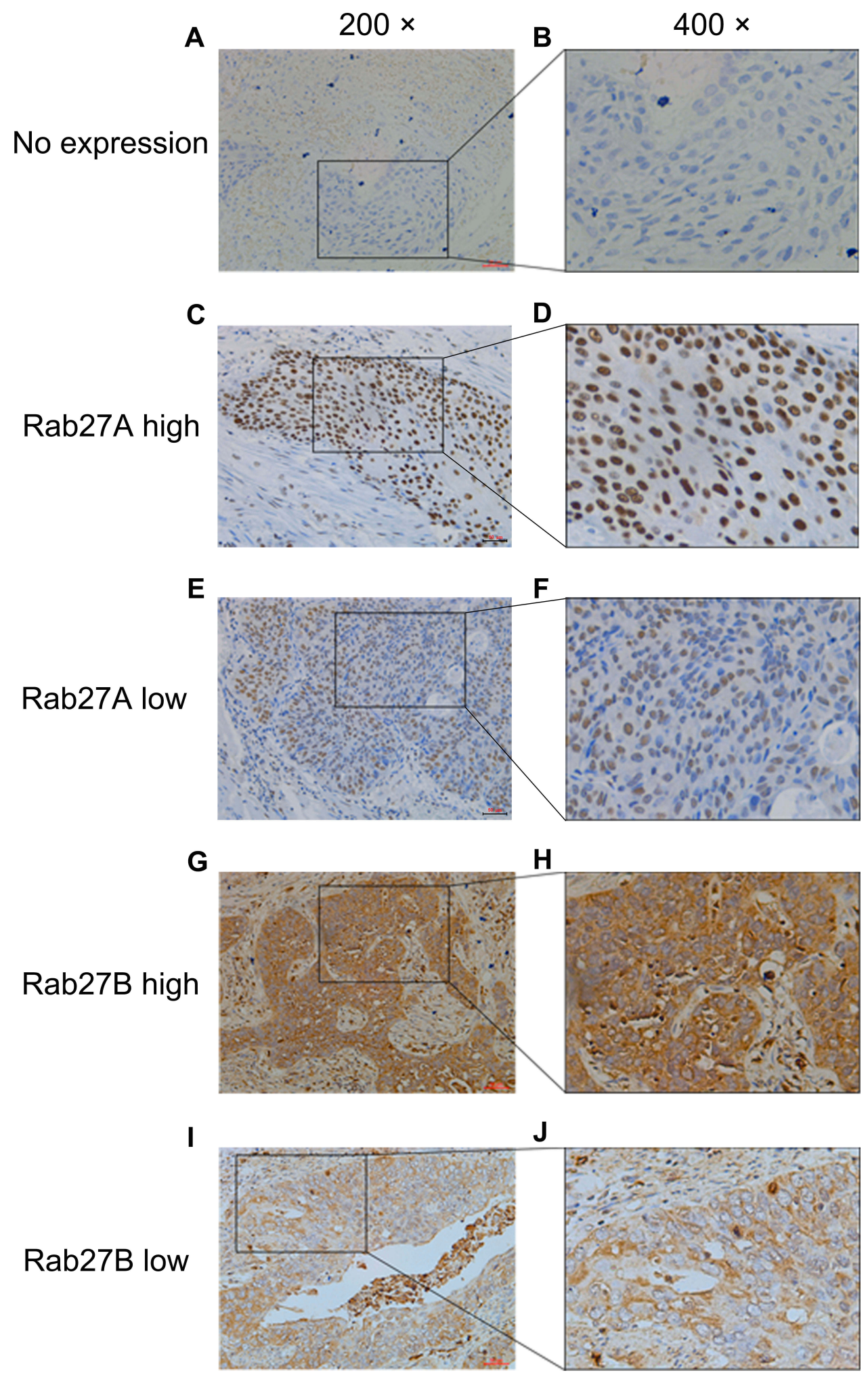

Figure I Representative pictures of Rab27A and Rab27B expression in ESCC tissues (left 200x, right 400x).

Notes: No expression of Rab27A and Rab27B in ESCC tissues (A and B). High expression of Rab27A (C and $\mathbf{D})$ and low expression of Rab27A (E and $\mathbf{F})$ in ESCC tissues. High expression of Rab27B (G and $\mathbf{H})$ and low expression of Rab27B (I and J) in ESCC tissues.

Abbreviation: ESCC, esophageal squamous cell carcinoma. 
was mainly located in cytoplasm. Next, Rab27A and Rab27B expression of 100 patients were categorized into the low expression group and the high expression group according to the evaluating score in materials. The results of correlations between Rab27A and Rab27B expression and clinicopathological features are summarized in Tables 1 and 2, respectively. The data demonstrated that high expression of Rab27A was notably associated with $\mathrm{N}(p=0.045)$ and TNM $(p=0.005)$ stage, while the other features, such as gender, age, location, tumor size, differentiation, and T stage, were poorly correlated with Rab27A expression. A roughly similar result was observed in the Rab27B group. High expression of Rab27B significantly correlated with $\mathrm{N}(p=0.033)$ and $\mathrm{TNM}(p=0.009)$ stage, and it also greatly related to tumor differentiation ( $p=0.013$ ), while the remaining features were not found statistically significant in the current study.

\section{Prognostic Value of Rab27A and Rab27B Expression in ESCC}

Kaplan-Meier analyses and combined analysis were carried out to explore the effect of Rab27A and Rab27B expression on overall survival (OS) in ESCC patients. The results showed that patients with high expression of Rab27A and Rab27B had worse OS as compared with

Table 2 Correlations Between Rab27B Expression and the Clinicopathological Features of ESCC Patients

\begin{tabular}{|c|c|c|c|c|c|}
\hline \multirow[t]{2}{*}{ Characteristics } & \multicolumn{5}{|l|}{ Rab27B } \\
\hline & No. Cases & Low Expression & High Expression & $\chi^{2}$ & $p$ value \\
\hline Gender & & & & 0.137 & 0.712 \\
\hline Male & 54 & 25 & 29 & & \\
\hline Female & 46 & 23 & 23 & & \\
\hline Age (years) & & & & 0.037 & 0.848 \\
\hline$\leq 60$ & 51 & 24 & 27 & & \\
\hline$>60$ & 49 & 24 & 25 & & \\
\hline Location & & & & 0.276 & 0.599 \\
\hline Upper/lower & 39 & 20 & 19 & & \\
\hline Middle & 61 & 28 & 33 & & \\
\hline Tumor size & & & & 1.327 & 0.249 \\
\hline$\leq 4 \mathrm{~cm}$ & 58 & 25 & 33 & & \\
\hline$>4 \mathrm{~cm}$ & 42 & 23 & 19 & & \\
\hline Differentiation & & & & 8.707 & 0.013 \\
\hline High & 35 & 22 & 13 & & \\
\hline Moderate & 52 & 24 & 28 & & \\
\hline Poor & 13 & 2 & 11 & & \\
\hline T (Primary tumor) & & & & 1.547 & 0.671 \\
\hline TI & 21 & 9 & 12 & & \\
\hline $\mathrm{T} 2$ & 9 & 6 & 3 & & \\
\hline T3 & 58 & 27 & 31 & & \\
\hline $\mathrm{T} 4$ & 12 & 6 & 6 & & \\
\hline N (Lymph node metastasis) & & & & 8.726 & 0.033 \\
\hline No & 52 & 32 & 20 & & \\
\hline $\mathrm{NI}$ & 32 & 12 & 20 & & \\
\hline N2 & 13 & 3 & 10 & & \\
\hline N3 & 3 & 1 & 2 & & \\
\hline TNM stage & & & & 8.036 & 0.009 \\
\hline$\leq 11$ & 49 & 30 & 19 & & \\
\hline$>I I$ & 51 & 18 & 33 & & \\
\hline
\end{tabular}

Note: Significant results $(p<0.05)$ are given in bold.

Abbreviation: ESCC, esophageal squamous cell carcinoma. 
A

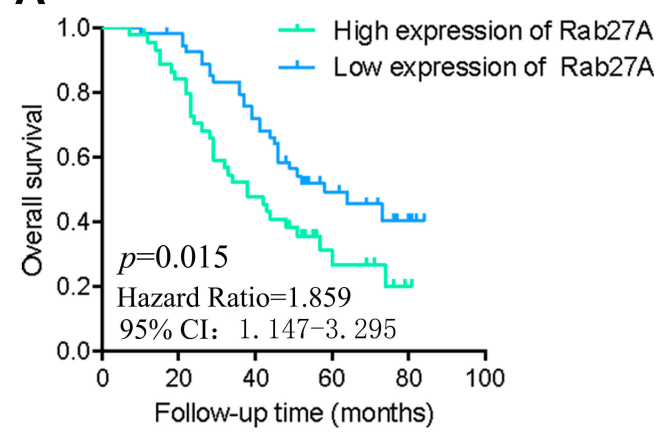

C

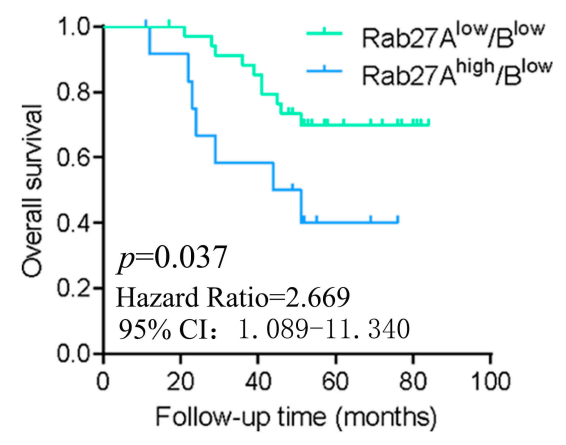

E

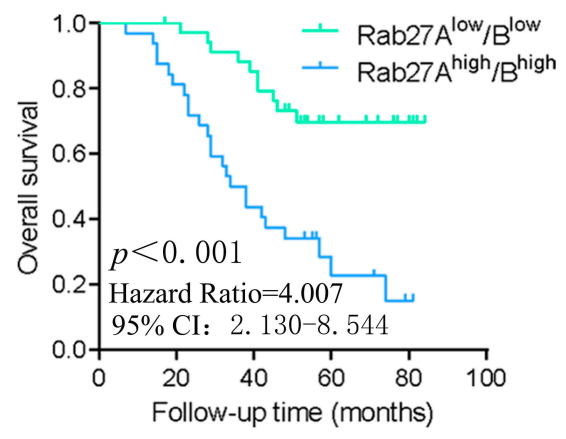

G

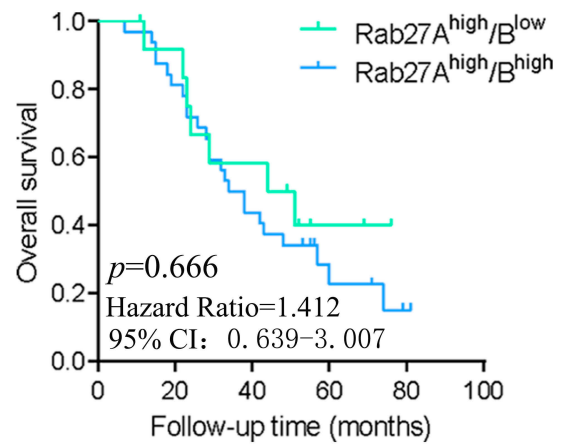

B

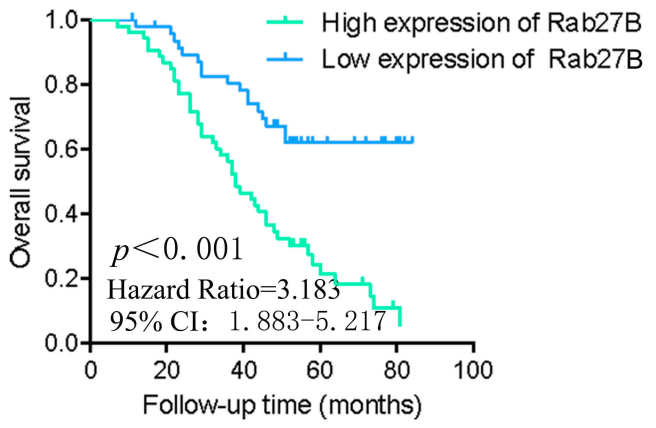

D

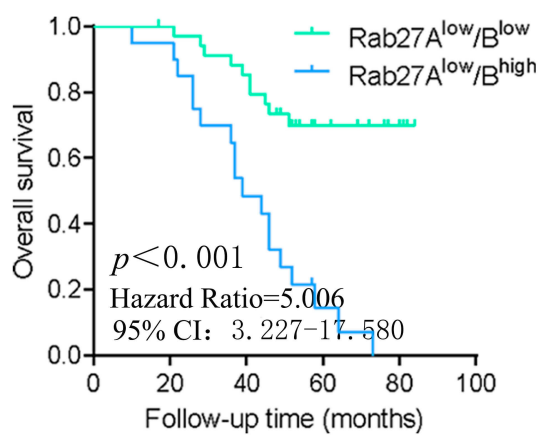

F

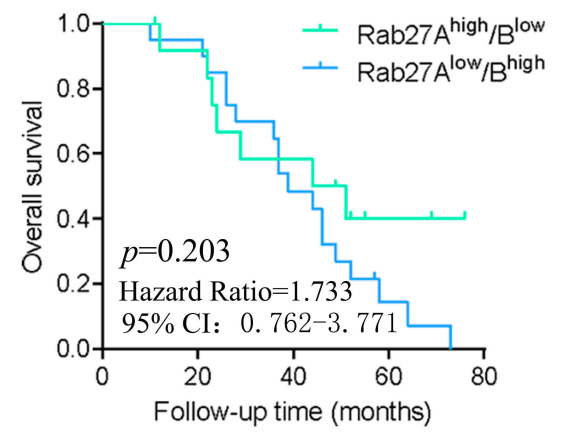

H

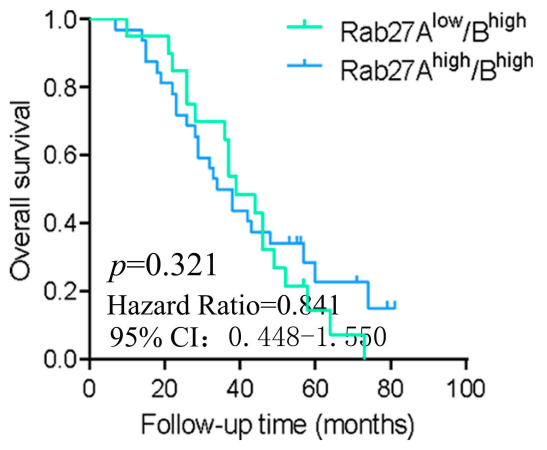

Figure 2 Prognostic value of Rab27A and Rab27B expression in ESCC tissues.

Notes: Kaplan-Meier OS curve in patients with high and low expression of Rab27A (A) and Rab27B (B). Combination analysis of Kaplan-Meier OS curve in patients in the Rab27A ${ }^{\text {low }} / B^{\text {low }}$ group and Rab27A $A^{\text {high }} / B^{\text {low }}$ group $(\mathbf{C})$, Rab27A ${ }^{\text {low }} / B^{\text {high }}$ group $(\mathbf{D})$, and Rab27A high $/ B^{\text {high }}$ group $(\mathbf{E})$, respectively (all $\left.p<0.05\right)$. Combination analysis of KaplanMeier OS curve in patients in the Rab27A $A^{\text {high }} / B^{\text {low }}$ group and Rab27A $A^{\text {low } / B^{\text {high }}}$ group $(\mathbf{F})$, Rab27A $A^{\text {high }} / B^{\text {low }}$ group and Rab27A $A^{\text {low } / B^{\text {high }}}$ group $(\mathbf{G})$, and Rab27A $A^{\text {high }} / B^{\text {high }}$ group and Rab27A ${ }^{\text {high }} / \mathrm{B}^{\text {high }}$ group $(\mathbf{H})($ all $p<0.05)$.

Abbreviations: ESCC, esophageal squamous cell carcinoma; OS, overall survival. 
Table 3 Univariate and Multivariate Analysis of Prognostic Factors in 100 ESCC Patients for Overall Survival

\begin{tabular}{|c|c|c|c|c|c|c|}
\hline \multirow[t]{2}{*}{ Characteristics } & \multicolumn{3}{|c|}{ Univariate Analysis } & \multicolumn{3}{|c|}{ Multivariate Analysis } \\
\hline & p value & $\begin{array}{l}\text { Hazard } \\
\text { Ratio }\end{array}$ & $\begin{array}{l}\text { 95\% Confidence } \\
\text { Interval }\end{array}$ & p value & $\begin{array}{l}\text { Hazard } \\
\text { Ratio }\end{array}$ & $\begin{array}{l}\text { 95\% Confidence } \\
\text { Interval }\end{array}$ \\
\hline Gender & 0.734 & 1.094 & $0.651-1.838$ & & & \\
\hline Age & 0.824 & 1.06 & $0.635-1.770$ & & & \\
\hline Location & 0.698 & 1.11 & $0.656-1.876$ & & & \\
\hline Tumor size & 0.921 & 0.974 & $0.579-1.638$ & & & \\
\hline Differentiation & 0.071 & 1.438 & $0.969-2.133$ & 0.890 & 1.028 & $0.692-1.528$ \\
\hline $\mathrm{T}$ (Primary tumor) & 0.519 & 1.095 & $0.83 I-1.44 \mid$ & & & \\
\hline $\mathrm{N}$ (Lymph node metastasis) & 0.001 & 1.595 & $1.208-2.108$ & 0.315 & 1.304 & $0.777-2.187$ \\
\hline TNM stage & 0.002 & 2.279 & $1.34 \mid-3.874$ & 0.559 & 1.303 & $0.536-3.169$ \\
\hline Rab27A expression & 0.018 & 1.861 & $1.114-3.107$ & 0.567 & 1.179 & $0.67 I-2.072$ \\
\hline Rab27B expression & $<0.001$ & 3.309 & $1.875-5.840$ & 0.003 & 2.694 & $1.414-5.132$ \\
\hline
\end{tabular}

Note: Significant results $(p<0.05)$ are given in bold.

Abbreviation: ESCC, esophageal squamous cell carcinoma.

those in the low expression group (Figure $2 \mathrm{~A}$ and $\mathrm{B}$ ). Moreover, the Rab27 $\mathrm{A}^{\text {high }} / \mathrm{B}^{\text {low }}$ group, Rab27 $\mathrm{A}^{\text {low }} / \mathrm{B}^{\text {high }}$ group, and $\mathrm{Rab} 27 \mathrm{~A}^{\text {high }} / \mathrm{B}^{\text {high }}$ group displayed a lesser OS rate than that in the Rab27 $\mathrm{A}^{\text {low }} / \mathrm{B}^{\text {low }}$ group (Figure $2 \mathrm{C}-\mathrm{E}$ ). However, the former three groups presented rare significance between each two comparisons (Figure 2F-H). Additionally, univariate and multivariate Cox regression analyses were performed to determine the prognostic value of each feature. As presented in Table 3, univariate analysis shown that $\mathrm{N}$ stage $(p=0.001)$, TNM stage $(p=0.002)$, Rab27A expression $(p=0.018)$, and Rab27B expression $(p<0.001)$ were significant prognostic factors for OS in ESCC. Surprisingly, we discovered that Rab27B expression was the independent prognostic factor for OS $(p=0.003)$ in multivariate analysis.

\section{Relationship Between Rab27A and Rab27B Expression in Esophageal Carcinoma}

We utilized GEPIA platform data from TCGA database to explore the relationship between Rab27A and Rab27B expression in esophageal carcinoma. The results suggested that Rab27A expression was positively correlated with Rab27B expression (Figure $3 \mathrm{~A}, \mathrm{R}=0.41, p<0.001$ ). Additionally, IHC scores of Rab27A and Rab27B expression were used to validated the correlation. The similar tendency was observed with our data (Figure 3B, $\mathrm{R}^{2}=0.4219, p=0.001$ ).

\section{Discussion}

The Rab family of small GTPases is a conserved family of cytosolic proteins controlling multiple intracellular transport
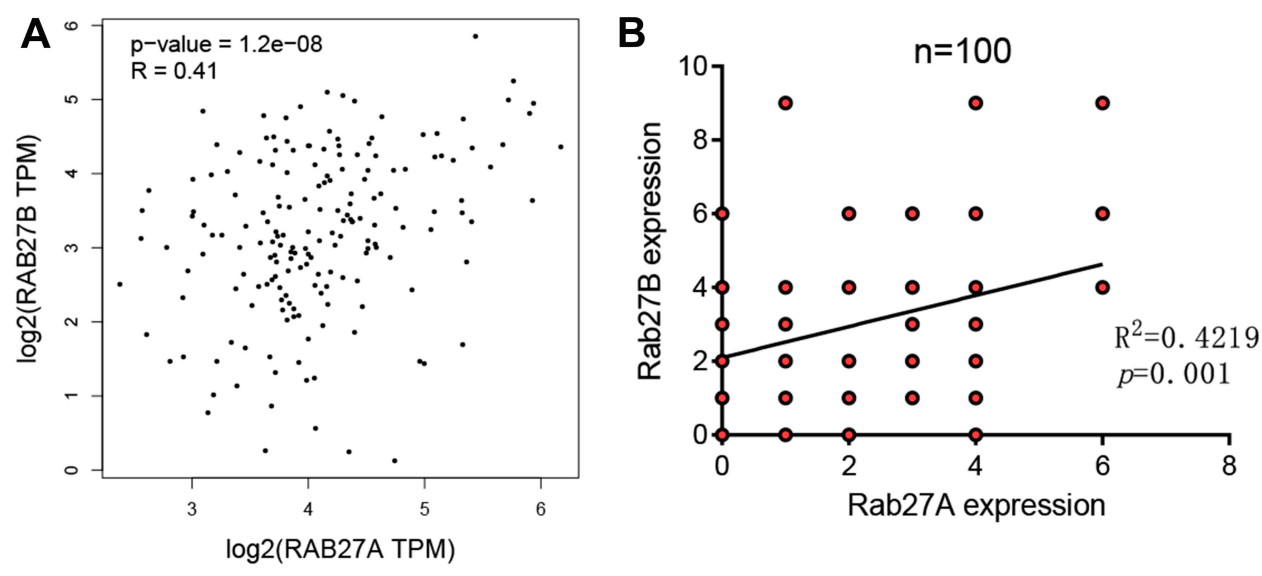

Figure 3 Relationship between Rab27A and Rab27B expression.

Notes: Relationship between Rab27A and Rab27B expression in EC from TCGA database (A) and in ESCC from our cohort (B).

Abbreviations: EC, esophageal cancer, ESCC, esophageal squamous cell carcinoma. 
pathways and diverse steps of vesicular trafficking. ${ }^{16}$ More than $70 \mathrm{Rab}$ proteins have been identified in humans, including Rab27A and Rab27B, which define exocytic events and participate in vesicle secretion into the extracellular environment. ${ }^{7}$ Numerous studies have reported that abnormal expression of Rab27A and Rab27B in different types of cancer plays a critical role in tumor progression and also serves as biomarkers for predicting prognosis of patients.

Rab27A was confirmed as an oncogenic factor to promote melanoma proliferation via ERK signaling. ${ }^{8}$ Previous studies have demonstrated that Rab27A was highly upregulated and could act as a valuable prognostic indicator, including in hepatocellular carcinoma, gliomas, colorectal cancer, and clear cell renal cell carcinoma. ${ }^{10,11,17,18}$ In present study, we observed that high expression of Rab27A in ESCC tissues exhibited a significant correlation with $\mathrm{N}$ and TNM stage. Furthermore, high expression of Rab27A had less OS, which is consistent with previous research. However, Rab27A mRNA expression was found to be downregulated in ESCC tissues compared with the adjacent normal tissues from TCGA databases, ${ }^{19}$ which is contrary to our findings. This may be explained by two reasons: 1) individual variation and racial difference; and 2) mRNA and protein level difference. More research tends to be required for investigating transcriptional regulation and more samples should be added to validate the expression level in ESCC.

Rab27B could provide proliferative and metastatic ability in estrogen receptor-positive breast cancer cells. ${ }^{12}$ Similarly, Rab27B knockdown remarkably inhibited invasion and proliferation in human pancreatic cancer cells. ${ }^{20}$ Koh et al found that up-regulated expression of Rab27B was significantly related to unfavorable prognosis in lung squamous cell cancers, pancreatic cancer, gastrointestinal tumors, and ovarian cancer. ${ }^{9,21-23}$ Here, our results showed that high expression of Rab27B was extremely correlated with $\mathrm{N}$ and TNM stage, and tumor differentiation, which contributed to inferior survival outcome in ESCC. In addition, Cox regression analyses demonstrated that Rab27B expression was the independent prognostic factor for ESCC. The results agreed with previous studies and suggested that Rab27B may act as potential predictor of outcome in ESCC. Conversely, another study indicated that Rab27A and Rab27B were frequently down-regulated in advanced prostate cancer, as well as negatively associated with patients' outcome. Personally, Rab27A and Rab27B could be involved in different molecular mechanisms in different tumors, which may result from tumor heterogeneity. Further studies would explain the exact mechanism.
Besides, we conducted combined analyses to better assess the prognostic value of Rab27A and Rab27B. The data showed that the $\mathrm{Rab} 27 \mathrm{~A}^{\text {low }} / \mathrm{B}^{\text {low }}$ group had a superior OS rate to the Rab27 $\mathrm{A}^{\text {high }} / \mathrm{B}^{\text {low }}$ group, Rab27 $\mathrm{A}^{\text {low }} / \mathrm{B}^{\text {high }}$ group, and $\mathrm{Rab} 27 \mathrm{~A}^{\text {high }} / \mathrm{B}^{\text {high }}$ group, which indicated that patients with low expression of Rab27A and Rab27B would appear to have better prognostic outcomes.

These clinical findings suggested that model construction of simultaneous detection of Rab27A and Rab27B would have implications on monitoring and predicting the prognosis of ESCC.

Interestingly, we also discovered that Rab27A expression had a positive relationship with Rab27B in TCGA database and could further be validated in our cohort. In the authors' view, this is mainly due to the fact that Rab27A and Rab27B possess 70\% homology and possibly bind to a similar set of effector proteins in ESCC, which will be certainly needed for further investigation.

To our knowledge, this was the first research to investigate the role of Rab27A and Rab27B on prognosis in ESCC simultaneously. Actually, there are several limitations in our research. Firstly, these results may be a result of selection bias when collecting enrolled patients. An organized study containing more cases will be required for further validation. Secondly, using IHC scores for evaluation expression levels is somewhat subjective. Finally, the follow-up time was relatively short, and further large-scale trials consisting of more samples and longer follow-up time would be much more convincing.

\section{Conclusion}

The present study clearly elucidates that Rab27A and Rab27B are highly expressed in ESCC, which indicates inferior prognosis in patients. These findings suggest that up-regulation of Rab27A and Rab27B may serve as reliable and clinically promising prognostic biomarkers to predict OS of ESCC patients after surgery.

\section{Acknowledgments}

This research was supported by Science and Technology Major Project of Fujian province (2017YZ0001) and the Startup Fund for scientific research, Fujian Medical University (Grant number: 2018QH2029). All authors would like to thank GEPIA and TCGA.

\section{Author Contributions}

Chun Chen conceived and designed the study. Fengqiang Yu performed the IHC experiment and wrote the manuscript. 
Weihan Wu and Mingqiang Liang collected patients' clinical data and analyzed the experimental data. Yu Huang assisted with experimental performance and data analysis. All authors read and approved the final manuscript. All authors made substantial contributions to acquisition of data, or analysis and interpretation of data, took part in drafting the article or revising it critically for important intellectual content, gave final approval of the version to be published, and agree to be accountable for all aspects of the work.

\section{Disclosure}

All authors declare no conflicts of interest in this research.

\section{References}

1. Siegel RL, Miller KD, Jemal A. Cancer statistics, 2019. CA Cancer J Clin. 2019;69(1):7-34. doi:10.3322/caac.21551

2. Abnet CC, Arnold M, Wei W-Q. Epidemiology of esophageal squamous cell carcinoma. Gastroenterology. 2018;154(2):360-373. doi:10.1053/j.gastro.2017.08.023

3. Li B, Hong P, Zheng -C-C. Identification of miR-29c and its target FBXO31 as a key regulatory mechanism in esophageal cancer chemoresistance: functional validation and clinical significance. Theranostics. 2019;9(6):1599-1613. doi:10.7150/thno.30372

4. Zerial M, McBride H. Rab proteins as membrane organizers. Nat Rev Mol Cell Biol. 2001;2(2):107-117. doi:10.1038/35052055

5. Stenmark H. Rab GTPases as coordinators of vesicle traffic. Nat Rev Mol Cell Biol. 2009;10(8):513-525. doi:10.1038/nrm2728

6. Seabra MC, Mules EH, Hume AN. Rab GTPases, intracellular traffic and disease. Trends Mol Med. 2002;8(1):23-30. doi:10.1016/S14714914(01)02227-4

7. Ostrowski M, Carmo NB, Krumeich S. Rab27a and Rab27b control different steps of the exosome secretion pathway. Nat Cell Biol. 2010;12(1):19-30. doi:10.1038/ncb2000

8. Fukuda M. Regulation of secretory vesicle traffic by Rab small GTPases. Cell Mol Life Sci. 2008;65(18):2801-2813. doi:10.1007/ s00018-008-8351-4

9. Koh HM, Song DH. Prognostic role of Rab27A and Rab27B expression in patients with non-small cell lung carcinoma. Thoracic Cancer. 2019;10(2):143-149. doi:10.1111/1759-7714.12919

10. Shi C, Yang X, Ni Y. High Rab27A expression indicates favorable prognosis in CRC. Diagn Pathol. 2015;10:68. doi:10.1186/s13000015-0303-3
11. Dong -W-W. Differential expression of Rab27A/B correlates with clinical outcome in hepatocellular carcinoma. World $J$ Gastroenterol. 2012;18(15):1806-1813. doi:10.3748/wjg.v18.i15.1806

12. An HJ, Song DH, Koh HM. RAB27A is an independent prognostic factor in clear cell renal cell carcinoma. Biomark Med. 2019;13 (4):239-247. doi: $10.2217 / \mathrm{bmm}-2018-0336$

13. Zhao H, Wang Q, Wang X. Correlation between RAB27B and p53 expression and overall survival in pancreatic cancer. Pancreas. 2016;45(2):204-210. doi:10.1097/MPA.0000000000000453

14. Zhao Y-R, Liu H, Xiao L-M, Jin C-G, Zhang Z-P, Yang C-G. The clinical significance of CCBE1 expression in human colorectal cancer. Cancer Manag Res. 2018;10:6581-6590. doi:10.2147/ CMAR.S181770

15. Tang Z, Li C, Kang B, Gao G, Li C, Zhang Z. GEPIA: a web server for cancer and normal gene expression profiling and interactive analyses. Nucleic Acids Res. 2017;45:W98-W102. doi:10.1093/nar/ gkx247

16. Rice TW, Ishwaran H, Ferguson MK, Blackstone EH, Goldstraw P Cancer of the esophagus and esophagogastric junction: an eighth edition staging primer. $J$ Thorac Oncol. 2017;12(1):36-42. doi:10.1016/j.jtho.2016.10.016

17. Akavia UD, Litvin O, Kim J. An integrated approach to uncover drivers of cancer. Cell. 2010;143(6):1005-1017. doi:10.1016/j. cell.2010.11.013

18. Wang H, Zhao Y, Zhang C. Rab27a was identified as a prognostic biomarker by mRNA profiling, correlated with malignant progression and subtype preference in gliomas. PLoS One. 2014;9(2):e89782. doi:10.1371/journal.pone.0089782

19. He W, Yan Q, Fu L, Han Y. A five-gene signature to predict the overall survival time of patients with esophageal squamous cell carcinoma. Oncol Lett. 2019;18(2):1381-1387. doi:10.3892/ol.2019.10449

20. Hendrix A, Maynard D, Pauwels P. Effect of the secretory small GTPase Rab27B on breast cancer growth, invasion, and metastasis. $J$ Natl Cancer Inst. 2010;102(12):866-880. doi:10.1093/jnci/djq153

21. Li J, Jin Q, Huang F, Tang Z, Huang J. Effects of Rab27A and Rab27B on invasion, proliferation, apoptosis, and chemoresistance in human pancreatic cancer cells. Pancreas. 2017;46(9):1173-1179. doi:10.1097/MPA.0000000000000910

22. Zhang Y, Zhang Z, Yang L. Prognostic value of Rab27B nuclear expression in gastrointestinal stromal tumors. Dis Markers. 2014;2014:942181. doi:10.1155/2014/594093

23. Ren P, Yang X-Q, Zhai X-L, Zhang Y-Q, Huang J-F. Overexpression of Rab27B is correlated with distant metastasis and poor prognosis in ovarian cancer. Oncol Lett. 2016;12(2):1539-1545. doi:10.3892/ ol.2016.4801

\section{Publish your work in this journal}

Cancer Management and Research is an international, peer-reviewed open access journal focusing on cancer research and the optimal use of preventative and integrated treatment interventions to achieve improved outcomes, enhanced survival and quality of life for the cancer patient.
The manuscript management system is completely online and includes a very quick and fair peer-review system, which is all easy to use. Visit http://www.dovepress.com/testimonials.php to read real quotes from published authors. 